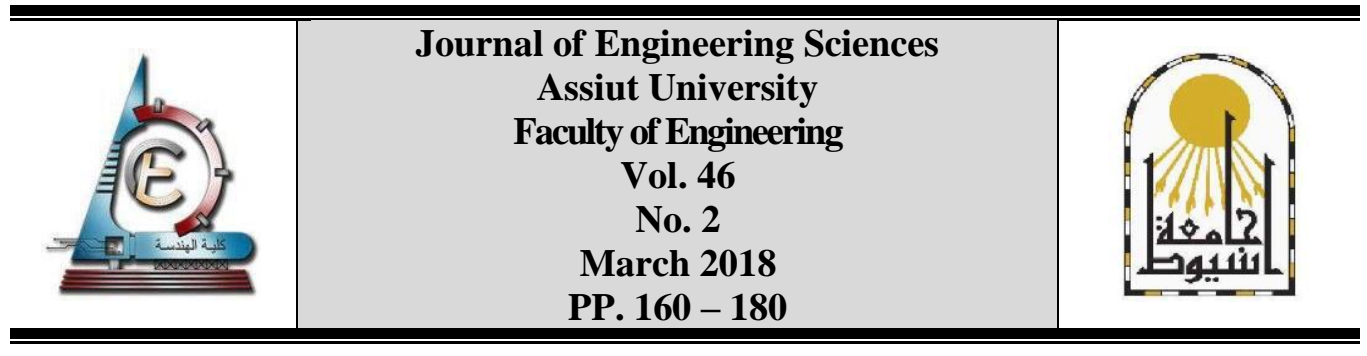

\title{
SOCIALLY SUSTAINABLE NEIGHBORHOODS IN EGYPT: ASSESSING SOCIAL CAPITAL FOR DIFFERENT NEIGHBORHOOD MODELS IN GREATER CAIRO REGION
}

\author{
Islam Ghonimi, Ahmed Awaad \\ Architecture Department, Shubra Faculty of engineering, Benha University, Egypt
}

Received 26 September 2017; Accepted 29 October 2017

\begin{abstract}
Social capital considers social networks that assure the correlation, cooperation and contraction between neighborhoods. Different scholars discussed the role of urban form in enhancing social capital. Changing development patterns from the traditional in old Egyptian cities to modern neighborhood in new Egyptian settlements creates a debate of their impacts on social capital. Based on case study of three types of neighborhoods, this research provides an understanding of the correlation between specific neighborhoods urban configuration and Social capital and social sustainability.

Keywords: Crime opportunities, crime rates, crime prevention through environmental design (CPTED), fear of crime, sense of safety and security, neighborhood urban patterns.

\section{Introduction}

Some neighborhoods encourage social sustainability, whereas others do not. An understanding of the reason that some neighborhoods provide more social capital than others is important to improve social sustainability. Traditional neighborhood types are mixed use and pedestrian oriented. Residents have daily services within walking distance. Theoretically, these types are most likely to enhance social capital. They are expected to enhance social capital because they enable residents to interact intentional or accidental. They can encourage a sense of trust and a sense of connection between people. To many residents, such contacts breed a sense of familiarity. They create a web of public respect and trust, and a resource in time of personal or neighborhood need, $[1,2,3]$.

On the Contrary, modern neighborhood types contain only houses and car oriented. Daily needs are not met in the neighborhood, so residents have to travel by car to find services. Theoretically, they are most likely to increase crime rates. They do little to enable social interaction. Social interaction is more likely to occur by invitation, not by chance encounter. Life is supposed to take place within the home or in the backyard. They are not places designed to encourage social interaction. Accordingly they discourage sense of trust and connection between people. Accordingly they lack sense of familiarity and knowing strangers, [4, and 5].
\end{abstract}


This study examines the relationship between neighborhood design and social capital. The main hypothesis is that traditional neighborhoods are more likely to encourage social capital than are car-modern neighborhoods in Cairo - Egypt.

\subsection{Research problem}

Egyptian context of modernization draw different typologies of new residential districts from globalized westernized world into Egyptian context. These patterns borrowed from social context that are different from local circumstances and may not be suitable for application in local circumstances. It could impact the social fabric of our cities and cause deep changes to social sustainability, and could build weak the social ties that properly embedded in social fabric of traditional cities. It could negatively impact social capital and social sustainability.

\subsection{Research aim}

This study aims to test the correlation which exists between neighborhoods urban configuration and social sustainability. Based on a case study in three residential neighborhoods in different chronological ages in Cairo-Egypt, The research assesses the role of neighborhood urban form in enhancing social capital.

\subsection{Research hypothesis}

This research assumes that the way we design our neighborhoods affects social capital and social sustainability. And that contemporary neighborhoods rather than achieve high social capital it could cause social problems.

\subsection{Research methodology}

The method used is inductive and involves a comparative analysis of different case studies, with different spatial configuration. It aims to test and compare the relation between neighborhood urban form and social capital on the other hand. The research depends on two interlocking stages: first, literature review to introduce the variables of the research, social capital in terms of concept, and measurable variables in addition to neighborhood urban configuration in terms of concepts, patterns and measurable indices. Finally, the relationship between the two variables is tested in a case study in two neighborhoods adjacent to criminal points. The field study goes through the following three steps: measuring social capital using questionnaire, and measuring the spatial configuration using spatial measures in each case study and finally testing the validity of their relations.

\section{Social sustainability and social capital}

A socially sustainable city must achieve social equity and equal opportunities in the distribution of development benefits and costs. Social sustainable urban form refers to the ability of a city to sustain orderly relationship among its diversified residents and to meet their hierarchy of needs. First: it depends on the economic efficiency of using the resources provided by natural resources. Second: it depends on economic growth with ensuring social equity in distribution of land uses and housing types. Third: it enhances public realm to support opportunities for economic exchange; it explains the importance of social networks and the way it precedes. Putnam Robert introduces the idea of social capital as analogy with other forms of economic capital that have similar benefits, not physical benefits but social capital refers to benefits of social networks. According to Putnam 
Robert, social capital is the connections among individual's social networks that facilitate networks, norms, social trust, coordination and cooperation for mutual benefit [6 and 7]

It suggests an understanding of social ties that facilitate co-operation, involvement, reconciling differences and trust. He stated that "working together is easier in community blessed with a substantial stock of social capital". [7]

It could indicate the strong or weak ties in social networks hence indicate the strong or weak social fabric. Interaction enables people to build strong communities, to commit to each other, to mesh themselves into a complex social fabric, and to knit the social fabric. There has been considerable evidence that communities with a high level of social capital are more likely to benefit from lower crime figures, better health, higher educational achievement, and better economic growth

Through this concept, Putman introduces understanding of community and its different social aspects like social involvement, co-operative action among citizens, and network trustbased voluntary associations as a constitute for civil society as the key source for social capital for communities. The social fabric of the city is a critical factor in social capital. Better understand of the impact of social fabric on social capital can be explained by discussing theories grounding social fabric, social networks, social capital, and networked urbanism. Harper developed a typology of different of social capital in five categories, as follow:

- Participation, social engagement, commitment- involvement in local groups, voluntary organizations, clubs, taking action about a local issue.

- Control, self-efficacy - perceptions of control and influence of community affairs, health, satisfaction with life.

- Perception of community level structures or characteristics - satisfaction with local area, perceptions of local services and local problems.

- Social interaction, social networks, social support - contact with friends, family, neighbors; depth of socialization networks; perceptions of social support.

- Trust, reciprocity, social cohesion - trust in other people, confidence in institutions, confidence in public services; perceptions of shared values; length of residence in area.

Formal and informal networks are central to the conceptualization of social capital. They are defined as the personal relationships which are accumulated when people interact with each other in families, workplaces, neighborhoods, local associations and a range of informal and formal meeting places Recently, networks have been categorized to distinguish between different types of social capital, These networks are:

- Bonding social capital - ties (normally strong ties) characterized by strong bonds e.g. among family members or among members of an ethnic group; good for "getting by"

- Bridging social capital - more distant ties (normally weak ties) characterized by weaker, less dense but more cross-cutting ties e.g. with business associates, acquaintances, friends from different ethnic groups, friends of friends, etc.; good for "getting ahead"

- Linking social capital - characterized by connections between those within a hierarchy where there are differing levels of power. It is different from bonding and bridging in that it is concerned with relations between people who are not on an equal footing. An example would be a social-services-agency dealing with an individual e.g. job searching at the Benefits Agency. 
Finally when Putnam Robert, reflected contemporary socio-economic politics on the decline from civil society and decline in social capital of the American society, he reminds with the same for traditional connected urban form that make people more civically engaged than its contemporary counterparts who lived in a contemporary gated urban form.

\section{Social capital and neighborhood design}

Theoretically, urban sociologists see the space as more than a physical space within which social processes operate; rather they found organization of space could enhance the social relation, integration and especially face to face co-presence. Putnam Robert discusses the connection between diversity and social connections or social capital in two contact theories 'the intergroup theory' and 'the constrict theory' [7].

According to the 'intergroup theory', more diversity implies more inter-ethnic tolerance and social solidarity [7].The reason is that 'as we have more contact with people unlike us, we overcome initial barriers of ignorance and hesitation and come to trust them more'. According to the 'Intergroup theory', the contact between groups is at a maximum when five conditions are met: equal status between groups, common goals to be reached, intergroup cooperation, support of laws and customs and the potential to friendship.

On the contrary, according to the 'constrict theory', suggests that ethnic diversity might reduce both in-group and out-group trust, in neighborhoods where ethnic diversity is higher trust become lower. The reason is that ' when the social context is more diverse in terms of ethnic groups, there are more people 'unlike you'. As a result, there are less people, with whom one can identify, resulting in fewer social connections and lower levels of trust. Ethnic diversity may correlate negatively with social trust.

Putnam Robert argues against the contradicting theories, which argue the opposite: that diversity fosters out-group distrust and in-group solidarity. Putnam Robert argue that this is a short-term process, and that on the long term societies have overcome such fragmentation by creating new compassing identities that dampen the negative effects of diversity', which discourage sense of crime complex and lack of trust in society at large. [7]

Moving to Houghton, argued that mixed community could build inclusive communities that tackle residential segregation and social division Houghton He argued that mixed communities is used variously to define neighborhoods that have a mix and encourage a greater diversity of incomes, tenures, housing types and sizes and uses; groups of people in terms of ethnicity, age and family structure; or that contain some all-embracing notion of 'social mix' which encompasses elements of all these things and people in all areas, in poor and non-poor neighborhoods. He argued that the goal of mixed community is to build inclusive communities.

Moving to Alan Berube, he argued that it is more important for policy to prevent detrimental non-mix than to pursue some idealized mix across the whole of the country. He argued for three themes to promote mixed communities:

The first: to avoid the concentrations of deprivation that could limit the life chances of people living within them, beyond their own personal circumstances. Those poor families would be less disadvantaged if they were not forced to overcome uniformly poor neighborhood conditions. So mixed communities improve quality of life and outcomes for disadvantaged people.

The Second: mixed communities can achieve greater success in delivering on key public services outcomes (e.g. crime, health, education) versus deprived communities. 
Also if people are more socially and economically integrated, it is easy to improve school performance, or reduce health inequalities.

The third: mixed communities could avoid entering cycle of decline especially for low income homogeneous communities, which enable to avoid invest in their regeneration; as they offer a range of housing options for individuals and families as they age, household size changes and income increases or decreases.

Moving to Jan Jacobs [2], she argued for the importance of diversity in public life of the city. It is the most effective place for socializing future generation, and for exchange and contact of knowledge, experiences, and information with other diverse social groups, which could perpetuate trust and unity. She sees diversity as the key factor of success of a city: the variety of commercial activities, cultural opportunities, inhabitants, visitors as well as the variety of tastes, abilities, needs and even obsessions are the engine of urban development. She argued that urban diversity provides a more favorable environment for economic development than urban specialization. Economic development should be understood because of innovations. Furthermore, a relevant diversity measure should take into account the degree of diversity of the inherent classes.

Young differs somewhat from other advocates of urban heterogeneity in that she accepts the domination of specific neighborhoods by single groups, as long as boundaries between neighborhoods remain blurred. However, she regards diversity as key to her goals:

In the ideal city life, freedom leads to group differentiation, to the formation of affinity groups, but this social and spatial differentiation of groups is without exclusion. ... The interfusion of groups in the city occurs partly because of the multiuse differentiation of social space. What makes urban spaces interesting, draws people out in public to them, gives people pleasure and excitement, is the diversity of activities they support

To summarize, the scope of successful social fabric stressed the importance of inclusionary social process between diverse housing types, and could enhance connection between city parts residents even they were of similar or diverse social groups and put these criteria for achieving strong social fabric, represented in the following: first, available shared public life (facilities, urban space, services, and walk ways); second, easy network to facilitate connection and interaction between different city parts; third, inclusionary social process, to insure the interaction between diverse housing types; and finally diversity of housing types, to insure the interaction between diverse housing types.

\subsection{Sutability to Egypt context}

Social Sustainability takes in consideration the appropriateness of new development patterns to socio-cultural fabric of Egyptian society that implies religion, culture aspects, social aspect, and Egyptian people preferences. Traditions, state that stability of society depends on good social relations among members of the society; especially between the rich and the poor. Egyptian people often prefer streets, buildings, neighborhood, and even the city filled of life and activities, to achieve Ulfa, Lama, and Wanass, They like neighborhoods to be abundant with life and activities thus are safe. They prefer familiarity and intimacy created through the gradual rootedness in a specific place to a long period based on gaining knowledge of others, place each other, know each other, and being able to place them. They prefer to feel satisfaction that comes through gathering people into one place. It indicates the mixture of different population that brings good and bad together. 
It aims to encourage public participation with other diverse community levels, and is considered a link to vital social life to enable the city to develop social relations and promote sense of engagements, involvement, and responsibility; In addition, it considers engaging citizen into the society politically and psychologically ,It aims to provide sense of safety and security for their residents and to self-reduce crime opportunities, surveillance, and territoriality without using reinforcement methods and physical instruments. Finally it aims to promote integrated mixed socio-economic diversity environments to create diversity of the amount housing types and the kind of human activities, i.e. walking, sitting, doing commercial exchanges, making pictures on a sidewalk, talking shared between them. [8 and 9]

Traditional districts encourage people to live and feel satisfaction through gathering, collecting and mixing people with different housing income level. Thus Egyptian people believe that traditional communities support their buildings, streets, neighborhoods and city to be safe and full of life. Religion, culture aspects, social aspect, and Egyptian people preferences, all constitute the socio-cultural factor. Traditions and religions advice that the peace and stability of society depend on good social relations among the members of society, The good relation between neighbors comes from large interest in the neighbor right, or in Arabic "Hak El Gar" which is some kind of a social contraction between neighbors especially the poor and the rich. When looking to social fabric from Islam Perspective, Islam stressed neighborhood right, Islam sees that neighborhood of poor and rich is necessary for safeguarding the poor class from eradiation of the rich by means of a revolution of the poor, [12].

The relation between the poor and the rich, Islam endeavors to bring the poor class nearer to the rich rather than to incite them to quarrel. In order to control the relation between the rich and the poor, Islam urges the rich to be generous with the poor, and urges the poor not to use any means of violence with the rich, rather to conciliate the two classes. And to prevent leading to class hatred and makes it possible for springs of brotherhood and solidarity to gush forth, [12].

Islam endeavors to bring the poor near the rich, on contrary to the communism proposes them to abolish the rich class in favor of the lower social class. Islam uses moderation in bringing the poor and the rich to protect both, and raise the poor social and economic conditions to the rich [12]. In addition, social connection with other social groups ensures the contraction between them, which raises another concept of neighborhood right or in Arabic "Hormet El Gar". The poor neighborhood right for his rich neighbor is not to attack him or criminally act against him, and on the other hand the rich neighborhood right for his poor neighborhood, to help the needy and give them "El Zaka", [12].

\section{Social capital measures}

The bulk of research on social capital rests on some factors which are easy to investigate: Residents interaction, Sense of community, Familiarity with public stranger's, Trust and reciprocity, Tolerance and empathy, and social interaction between different housing income groups, Safety and security social diversity. 
JES, Assiut University, Faculty of Engineering, Vol. 46. No. 2, March 2018, pp.160-180

\section{Table 1.}

Social capital measures, ref. [5]

\begin{tabular}{|l|l|l|}
\hline So1 & Social Interaction & $\begin{array}{l}\text { Intentional and accedential interaction Between similar social } \\
\text { groups and different social groups }\end{array}$ \\
\hline So2 & Social Equity & Access to services and facilities and Diversity of housing \\
\hline So3 & \multicolumn{2}{|l|}{ Mixed Communities and diversity } \\
\hline So4 & Social Cohesion and Inclusion \\
\hline So5 & Sense of Safety & Feel Safe, Surveillance, know Strangers, and Target Hardening \\
\hline So6 & Distinctiveness & Sense of Identity, Belonging, and Sense Community \\
\hline So7 & Stewardship & Engagements, Involvment, Civic participation, Contraction and Responsibility. \\
\hline So8 & Political Participation & \\
\hline So9 & Trust and Solidarity & Strangers Familiarity, Tolerance and Empathy \\
\hline
\end{tabular}

\section{Urban pattern characteristics and social capital}

The Correlation between social capital and urban form has been frequently found in numerous studies. A current debate exists between scholars for the role of modern versus traditional patterns in their impacts on crime prevention.

Regarding land use pattern, some scholars found traditional districts keys for achieving social capital in urban spaces. They take in consideration that high- mixed-land uses variation of activities to provide residents with daily services within walking distance, accordingly attracts people continuous movement during day and night, and accordingly assures the interaction intentionally and accidentally, [8 and 9].

They found that complete removal of nonresidential uses from residential area could create negative spaces that fails to attract residents and discourages residents to be socially engaged.

Regarding housing income mix, some scholars found that mixed housing income is expected to increase the interaction between different social groups and encourages the sense of trust and sense of connection between residents. This could increase the sense of familiarity of other housing income Groups and create social web of public respect and trust, [2 and 5].

According to the 'intergroup theory', more diversity implies more inter-ethnic tolerance and social solidarity. The more contact with unlike people, makes residents overcome initial barriers of ignorance and start to trust them, [7].

For them ethnic diversity may reduce criminality and increase sense of safety and security. On the contrary, other scholars found that separate income could achieve homogeneity between residents, accordingly apply shared values and interests and there would be No social tension exists between community residents.

According to the 'constrict theory', Suggests that ethnic diversity might reduce both ingroup and out-group trust, because as ethnic diversity becomes higher the trust becomes lower. The reason is that ' when the social context is more diverse in terms of ethnic groups, there are more people unlike you. As a result, there are less people that each resident can identify, resulting in fewer social connections and lower levels of trust for them, ethnic diversity encourages criminality and reduces sense of safety and security.

Regarding Housing-income difference between neighborhood and adjacent community, some scholars found that locating similar low income neighborhood near to poor residents 
reduces social tension between residents and accordingly reduces crime rates. On the contrary, other scholars found that locating high income neighborhood adjacent to poor community could increase social benefits through creating a relation between different social groups; it creates much more social capital. It reduces social tension and accordingly reduces crime rates. [7and 10]

Regarding street network pattern, some scholars found that modern hierarchical street network pattern could define territoriality, achieve natural surveillance, and creates security parries that makes residents know each other and creates relationship between residents and creates strong social bonds. They recommend that moving from public grid pattern to private cul-de-sac pattern could increase Social bond and relations and achieve high social capital. Cul-de-sac patterns are pattern that Newman stressed in his theory of defensible space to exclude the intrusion of strangers in the space, [11and 13].

Regarding mixed use and mixed income, The mixed income and mixed communities with socio-spatial use inclusion to be able to ensure the relationship between diverse social groups and enhance social trust between community residents and adjacent community residents, and accordingly creates connected societies and increase social capital. Whereas separate income and separate use communities depend on socio-spatial segregation and exclusion, could lead to the lack of the relationship between diverse social groups and would discourage social trust between community residents and adjacent community residents which accordingly creates polarized societies and reduces social capital, Regarding urban hierarchy, some scholars consider urban form hierarchy that creates cluster closed pattern surrounding public spaces is a good tool to define shared norms, territorialities, responsibility and interests in urban spaces. It could create actions among individual's social networks that facilitate networks, norms, social trust, coordination and cooperation for mutual benefit. On the contrary, other scholars found that moving to public grid gives streets the byproduct of movement, through movement that makes it become more save. It increases streets critical role of urbanity and social interaction and accordingly it is not a place for enhancing social capital, [10].

Regarding density, some scholars found that increasing density and community size would increase dense concentration that increases the chances of people interaction between each other, [8 and 11].

On the contrary, other scholars found that increasing community size makes it difficult to define users and strangers and accordingly reduces residents willing to know each other's, [13].

Accordingly a current debate exists between scholars to define the role of modern versus traditional neighborhood characteristics in reducing crime rates and increasing resident's sense of safety and security. The following part of the research is developed to test the validity of such assumptions in the case of Cairo Egypt. Theoretically, successful neighborhood should create strong social fabric that encourages interaction, cross fertilization, creative exchange, and flow of ideas to enrich its Knowledge base, and enhance social life between different social groups and increase social trust, mutual benefits, co-operation, community tolerance and empathy.

So as to achieve this urban form must encourage co-presence -face to face- interaction between people especially from different social groups; this requires chances for meeting and interaction domain which maintains a network where an individual knowledge and experience redefines another and to continue as a cellular social fabric. Through validate 
social mix, public spaces, services, transportation so as to increase possibilities for meeting and interaction. To achieve strong social fabric different aspects are needed to be checked: among social critics of good socio-spatial configurations, the interaction between different parts of the city, especially the diverse ones, can be achieved through.

\section{The case study of three categories of neighborhoods in Cairo}

The objective of this research is to trace any statistical significant differences in responses to social capital indicators across different categories of neighborhoods. The case study based on three categories of neighborhoods in different development stage in Cairo. The relationship between neighborhood design and social capital will be examined.

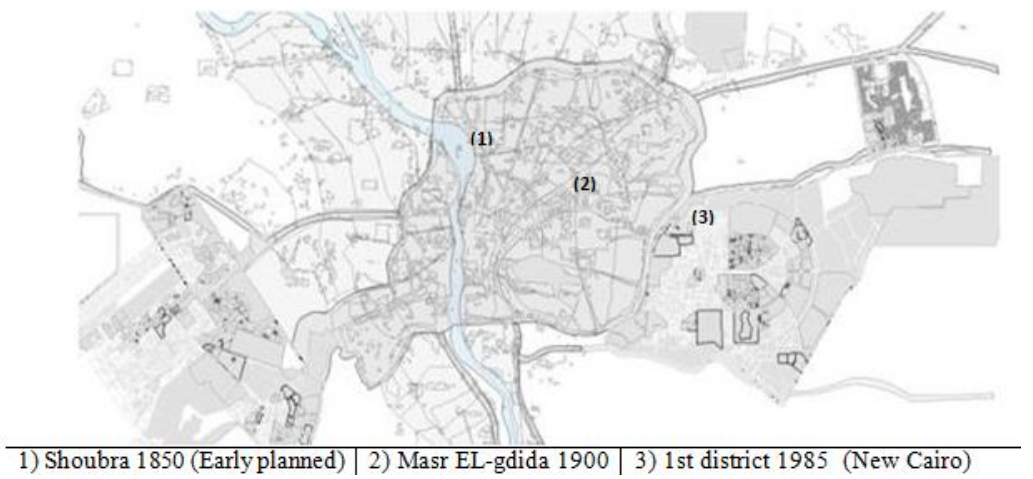

Fig. 1. places cases of study ref. [researcher]

The case study of traditional early developed, traditional early planned and modern new planned cities in Cairo will be investigated. Figure (1) includes a representation of three types of settlements in Greater Cairo Region, the traditional central early developed, the traditional early planned and the flourish of new settlements to the west and the east. Their socio-spatial difference is measured and the social capital indicators are projected to enable a comparison between them, [15]

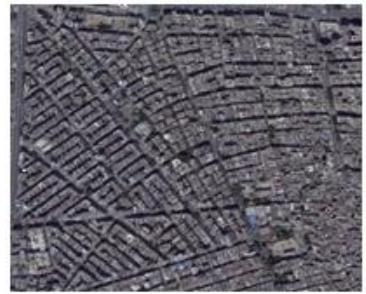

Shoubra 1850

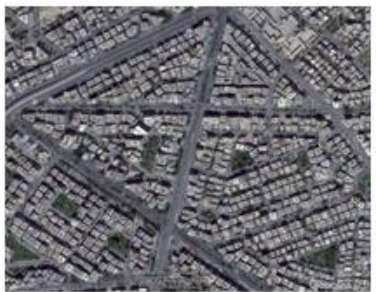

Masr EL-gdida 1900

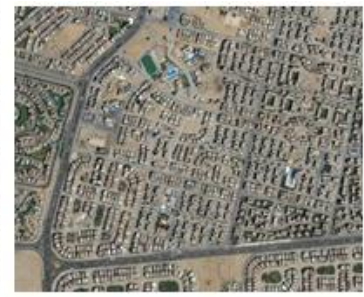

1 st district 1985

Fig. 2. planning patterns for cases of study (source, researcher)

Figure (2) represents the selected research concerns of three types of neighborhoods to present different urban planning pattern; the traditional early developed Shubra, the traditional early planned Heliopolis and the modern new planned New-Cairo City.

\subsection{Selection of case study areas}

Three neighborhoods were selected to present different categories of physical and social attributes, as shown in Figure 3. Shubra, Heliopolis and New Cairo city are selected to present different types of neighborhoods in Egypt. 

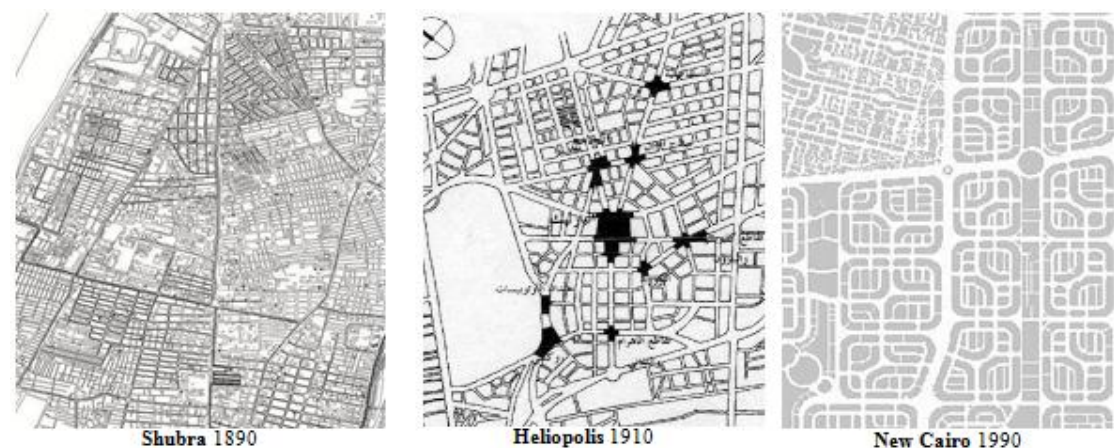

Fig. 3. Selected Case study Heliopolis and New Cairo City, (ref, researcher)

\subsection{Data collection and classification}

The purpose is to measure the impact of neighborhood design on social capital. Two forms of data collection were used - the first to measure urban form patterns based on spatial data, and the second to measure social sustainability data represented in the social interaction (intentional and accidental), (Between different housing groups, similar housing groups), safety and security in their neighborhood, based on questioner. Finally, Analyzing and discussing the results, these measures are used to investigate the variations between three case studies in achieving social capital, define the most social capital, and deduce the correlation between urban form and social capital [15].

\subsubsection{Measurements of Neighborhood urban configuration patterns:}

Urban form data were collected using surveying maps, observation, satalite maps, photographic images to document and explore neighbourhoods urban configuration patterns including land-use pattern, housing income pattern, street network pattern, and other urban spaces charachterstics including density, urban form, building heights, urban herarcheiy, and walkway forms, and finally landscape elements including lighting, greening. The data gathered for each case study related to urban configuration for each neighbourhood are gathered, measured and scored in Table 2. Recorded urban form data is categorized starting from the traditional type ending with the modern type and the scored result is converted into percentage, with keeping traditional pattern as higher percentage value than modern patterns [15].

1- Land use pattern can be classified under heading of landuse type, variation and density. The (dividing vs. connecting) line between different land-use represents the degree of mixed vs. separation of land use, [12].

2- Housing pattern can be classified under heading of housing type, variation and density; they can be measured using the (dividing vs. connecting) line between housing types. It represents the exclusion vs. segregation of housing types as a manifestation of political regime, [14].

3- Street network pattern can be classified under three categorize grid, loop, and tree patterns. Their spatial structure can be classified under heading of type of street, Linear feet of streets, No. of blocks, No. of intersections, No. of access point, No. of cul-de-sacs, Percentage of streets area.

4- Building Height ranges between low height 1 to 3 floors, mid height 4 to 5 floors, and tall height 6 to 8 floors. 
5- Community Density ranges between low density (60Person/Fedan), Middle density (120 Person/Fedan) and High Density (200 Person/Fedan) Also community size is measured and ranged between small, medium and large community size.

6- Urban form hierarchy is ranged in one hand between public, semipublic, and private in the other hand between grids versus cluster.

Table 2.

Shows a Comparison between urban forms of early-developed, early-planned and newly-planned settlements, ref. [15].

\begin{tabular}{|c|c|c|c|c|}
\hline & Traditional Early Planned & Traditional Early Developed & Modem New Planned \\
\hline & & Khalafawy- Shubra & Medan El Gama - Heliopolis & Jasmine, New Cairo City \\
\hline \multicolumn{5}{|c|}{ Micro Scale } \\
\hline \multirow{10}{*}{ 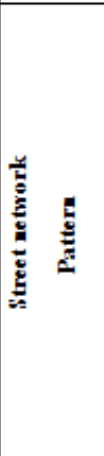 } & Type & Grid & Grid & Hierarchical (Loops \& col-de-sac) \\
\hline & Orientation & Outward oriented & Outward oriented & Inward oriented \\
\hline & Relation & Continuity with surroundings & Continuity with surroundings & Contrast with surroundings \\
\hline & No. of access point & 72 & 31 & 4 \\
\hline & No. of continuous & 53 & 14 & 2 \\
\hline & No. of intersections & 107 & 55 & 16 \\
\hline & No. of loops & 0 & 0 & 8 \\
\hline & No. of cul-de-sacs & 0 & 0 & 0 \\
\hline & No. of blocks & 180 & 63 & 20 \\
\hline & Road percentage & $10-20 \%$ & $20-30 \%$ & $30-40 \%$ \\
\hline \multirow{3}{*}{$\begin{array}{c}\text { Land-use } \\
\text { pattern }\end{array}$} & Type & Varied land use type & Varied land use type & Single land use type \\
\hline & Density & High density & Medium density & Low density \\
\hline & Mix & Mixed uses & Mixed uses & No variation\& nor mixing \\
\hline \multirow{3}{*}{$\begin{array}{c}\text { Housing } \\
\text { pattern }\end{array}$} & Type & Varied housing partems & Varied housing pattems & Single housing pattem \\
\hline & Density & $800-1600 \mathrm{p} /$ fed High density & $400-600 \mathrm{p} /$ fed medium density & $60-120 \mathrm{p} /$ fed Low density \\
\hline & Mix & Mixed housing type & Mixed housing type & No variation \& no mixing \\
\hline
\end{tabular}

\subsubsection{Measurements of social capital}

Measuring Social Capital depends on a questionnaire administered to district residents. Sample selection: 40 residents are randomly selected in each case study area that represents different gender, age, education and income. The questionnaire measured the key factors of social capital indicators in the three cases. Likert scale was used and has been converted into percentage scale. Questions first explore resident's socio-economic characteristics then it investigates their interaction level and type, reciprocity and trust, safty and security, i.e. how they well feel safe and secure for their families, children and wifes to move freely in the community, and for their properties. How well they knew their neighbors, how well they trust or faith in other people, and their social engagement. These dependent variables were measured as described in the following paragraphs:

The variable "Social interaction", measures resident's interaction to make them know each other and accordingly distinguishes who are strangers in the community. It enables collective involvement efficiency to define strangers and especially offenders and to face their criminal acts. This criterion rests on some questions: to what degree it allows clear 
sight line?' minimize isolation? And to what degree it increase residents ability to know and define neighbors, strangers, and criminals. These criteria can be measured using observation and questionnaire.

The variable type of interaction (accidental, intentional) measures the degree of interaction quantity (times/day) and interaction type (same or diverse social groups).

The variable "know Neighbors Measure" was measured whether and to what degree residents are able to recognize neighbors in streets.

The variable "Meet Neighbors Measure" was measured whether and to what degree residents be able to recognize neighbors in streets accidently or intentionally.

The variable "Social Engagement with Neighbors' Measure" was measured whether and how well they know their neighbors inside the community, and the adjacent community. How many times they share them in vacations, invited them to their homes, and is invited to their neighbor's homes; these questions probe the degree to which resident engage with their neighbors.

The variable "Depth of Social Relations" measures degree of contact with friends, family, neighbors; depth of socialization networks; perceptions of social support.

The variable "Where to Meet Neighbors Measure" was measured whether and to what degree residents be able to recognize neighbors in streets accidently or intentionally.

The variable "Feel of Safety and Security Measure" was measured whether and to what degree residents feel safe for movement in streets, in parks and facilities, safe in homes, safe for properties, safe for wife and kids and all age group people. For what degree he feels safe during day hours, during night hours, till late night. These questions probe the degree to which resident's perception and sense of safety and security.

The variable "Feel of Trust with neighbors Measure" measures whether residents feel trust in neighbors, whether they thought people were fair, and whether they thought most people try to be helpful.

The variable "Distinctiveness, Sense of identity and belonging, Sense of community Measure" measures the unique quality of a place that gives its particular character and increase residents feeling of stewardship and responsibility. Improved by making Spaces have a clear perceptual identity, one space should not feel like many others, difference, variety, and change between different places.

The variable "Stewardship measure" measures membership, influence, integration and fulfillment of needs, and shared emotional connections, McMillan Chavis Refers to shared values, norms, and identity.

The variable "Participation, social engagement Measure" measures whether and to what degree residents are able to commitment- involvement in local groups, voluntary organizations, clubs, taking action about a local issue.

The variable "Stewardship, responsibility, involvement, contraction, and civic participation" measures residents perception of ability to influence local affairs, and the confidence in civic institutions. Also refer to informal social network just like community associations, number of cultural, leisure; social groups belonged to, involvement with 
JES, Assiut University, Faculty of Engineering, Vol. 46، No. 2, March 2018, pp.160-180

voluntary organizations, religious activity with exploration of frequency and intensity of involvement in each one.

The variable "Democratic participation measure" measure people equal opportunities to participate in a democratic society on mutually agreeable terms in influencing choices for development and in decision-making [7]. It also measures no. of civil societies in the area, ability for collecting actions.

All previous measures are used to create a variable called "neighborhood social sustainability measure" which is an additive index of the all variables. It have been gathered, measured and scored in percentage in Table 3.

Table 3.

Shows Measured Social Indicators (in percentage). Ref. researcher

\begin{tabular}{|c|c|c|c|c|}
\hline \multirow{2}{*}{\multicolumn{2}{|c|}{$\begin{array}{l}\text { Social Sustainability } \\
\text { Assesment Factors }\end{array}$}} & \multirow{2}{*}{$\begin{array}{c}\text { Shubra } \\
\text { NHI }\end{array}$} & \multirow{2}{*}{$\begin{array}{c}\text { Heliopolis } \\
\text { NH2 }\end{array}$} & \multirow{2}{*}{$\begin{array}{c}5^{-} \text {districts } \\
\text { NH3 }\end{array}$} \\
\hline & & & & \\
\hline \multirow{5}{*}{ Social Interaction } & Intentional interaction measure & $90 \%$ & $80 \%$ & $30 \%$ \\
\hline & Accedential interactionmeasure & $90 \%$ & $80 \%$ & $10 \%$ \\
\hline & Between similar social groups & $30 \%$ & $80 \%$ & $0 \%$ \\
\hline & Between different social groups & $30 \%$ & $80 \%$ & $0 \%$ \\
\hline & & $60 \%$ & $80 \%$ & $15 \%$ \\
\hline \multirow[t]{3}{*}{ Social Equity } & Access to services and facilities & $90 \%$ & $90 \%$ & $10 \%$ \\
\hline & Diversity of housing & $40 \%$ & $90 \%$ & $10 \%$ \\
\hline & & $65 \%$ & $90 \%$ & $10 \%$ \\
\hline \multicolumn{2}{|c|}{ Mixed Communities } & $30 \%$ & $80 \%$ & $40 \%$ \\
\hline \multicolumn{2}{|c|}{ Social Cohesion and Inclusion } & $70 \%$ & $80 \%$ & $20 \%$ \\
\hline \multirow{5}{*}{ Sense of Safety } & Feel Safe Measure & $60 \%$ & $80 \%$ & $40 \%$ \\
\hline & Surveillance Measure & $70 \%$ & $80 \%$ & $30 \%$ \\
\hline & know Strangers Measure & $60 \%$ & $80 \%$ & $70 \%$ \\
\hline & Reduced Target Hardening & $90 \%$ & $80 \%$ & $10 \%$ \\
\hline & & $30 \%$ & 8096 & $90 \%$ \\
\hline \multirow{4}{*}{ Distinctiveness } & Sense of identity Measure & $70 \%$ & $80 \%$ & $60 \%$ \\
\hline & Sense of belonging Measure & $70 \%$ & $80 \%$ & $40 \%$ \\
\hline & Sense of community Measure & $60 \%$ & $80 \%$ & $50 \%$ \\
\hline & & $70 \%$ & $80 \%$ & $\mathbf{5 0 \%}$ \\
\hline \multirow{5}{*}{ Stewardship } & Involvment Measure & $90 \%$ & $70 \%$ & $20 \%$ \\
\hline & Civic participation Measure & $90 \%$ & $70 \%$ & $20 \%$ \\
\hline & Social Participation & $90 \%$ & $70 \%$ & $20 \%$ \\
\hline & Conteraction Measure & $90 \%$ & $70 \%$ & $20 \%$ \\
\hline & & $90 \%$ & $70 \%$ & $20 \%$ \\
\hline \multicolumn{2}{|c|}{ Political Participation } & $90 \%$ & $80 \%$ & $30 \%$ \\
\hline \multirow{2}{*}{$\begin{array}{l}\text { Trust and } \\
\text { Solidarity }\end{array}$} & Strangers familianity & $90 \%$ & $70 \%$ & $10 \%$ \\
\hline & Tolerance and empathy & $90 \%$ & $70 \%$ & $10 \%$ \\
\hline \multicolumn{2}{|l|}{ Sum Percentage } & $60 \%$ & $\$ 0 \%$ & $30 \%$ \\
\hline
\end{tabular}

\subsection{Results and discussion}

This part aims to discuss two interlocking issues, the first regarding the relation between neighborhood model and social capital in term of all social sustainability indicators to define how it varies across neighborhood categories, The second regarding the correlation between urban characteristics and social capital measure.

\subsubsection{Analysis of social sustainability indicators}

This part analyses the variation of each social sustainability indicators across the three categories of neighborhoods. In terms of social interaction, Social Equity, Social Cohesion, 
Mixed Community, Social Cohesion, Safety and Security, Stewardship, Distinctiveness, Political participation, Trust and Solidarity.

\subsubsection{Social interaction type}

Figure (4) compares different interaction levels in case studies, it illustrates that Shubra and Heliopolis recorded high interaction levels, this in comparison to 5th district that recorded lower interaction level. This can be explained as Shubra and Heliopolis revealed successful streets, shaded sidewalks and welcoming public domain that encourage walkability and generates common ground for residents to increase chances for meeting each other, connect to their community, know their neighbors and trust them. New Cairo revealed unwelcoming streets; sun shiny sidewalks and unwelcoming public domain discourage walkability and reduces the chances for meeting residents and knowing each other.

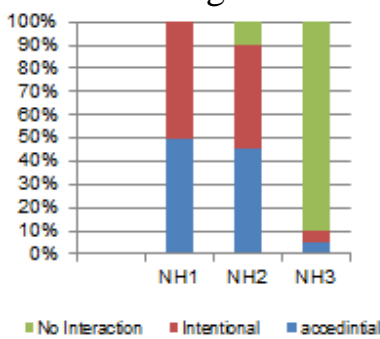

Fig. 4. Social Interaction in Percentage

\subsubsection{Social interaction level (intentional, accidental)}

Figure (5) compares different interaction types in case studies, it illustrates that Shubra and Heliopolis recorded high accidental interaction levels, interaction more likely happen intentionally and accidental between residents. On the contrary 5th district recorded lower accidental interaction level. Social interaction is more likely to occur by invitation, not by chance encounter. This can be explained as follow: Its travel routes and public spaces create large common areas that are shared by all residents and passengers and different social groups that facilitate interaction.

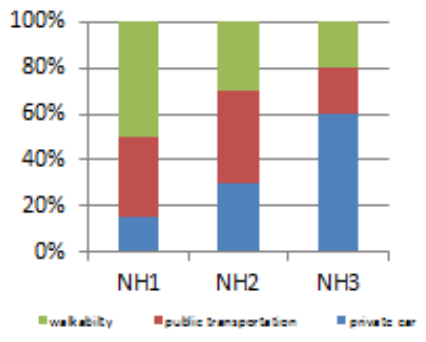

Fig. 5. Social Interaction in Percentage

Its relative high density and community size increases chances of interaction between residents. Its relative mixed use and mixed housing income gives residents the chance for diverse interact between residents and increases chance to exchange their experiences with other social groups. It could become an effective place for socializing future generation, and for exchange and contact of knowledge, experiences, and information with other diverse social groups. It provides diversity and variety of commercial activities, inhabitants, visitors, tastes, and needs.

This can be explained as follow: Its traveling routes become left over's and out of life from residents and diminish its social role as part of public life. In addition, It do not 
provide common shared public spaces by residents as in traditional cities, which increase the distance between different social groups and discourage interaction of diverse residents participation in social life. Its relative low density and community size do not support sufficient viable range of social interaction and relation between residents. Its relative separate use and separate income lakes the efficient provision of diversity and choices of social relations between diverse groups.

\subsubsection{Safety and security}

Figure (6) compares sense of safety and security in case studies, it reveals that Shubra and Heliopolis record a common sense of safety and security between residents in their homes and in streets and public areas. This can be explained as follow: Its mixed use encourages walkability and public realm and attracts people continuous movement during day and night that provide continuous surveillance. Its relative high density and high community size provide sufficient dense concentration of people that avoid empty spaces, make spaces full of people; accordingly, it will ensure a relatively high degree of continuous natural surveillance that provides residents with sense of safety and security. Beside the high relationship exist between their residents make them define strangers and define criminals, accordingly reduce crime rates.

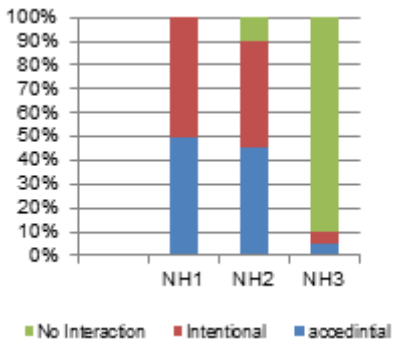

Fig. 6. Social Interaction in Percentage

Figure (6) reveals that New Cairo records a general sense of insecurity between residents in their homes and in streets and public areas. This can be explained as follow: Its separate use split service area from residential area reduces through movement of people and cannot animate streets, it loses life, and streets are empty. Its relative low density and community size make streets empty of passengers, accordingly reduce natural surveillance and supervision all day and night and reduce sense of safety and crime rates. In addition, residents hardly know each other and lake trust and faith in their neighbors and hardly recognize strangers and offenders, [13and 15]

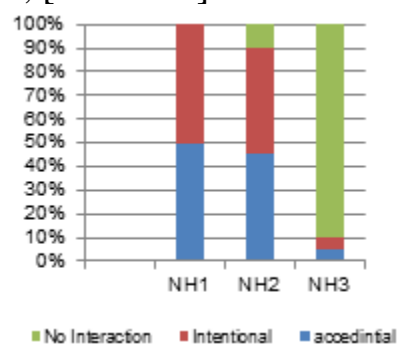

Fig. 7. Social Interaction in Percentage

\subsubsection{Community diversity}

Figure (7) compares community diversity in case studies, It revealed that Shubra and Heliopolis records a general diversity and mix in building types, heights, shapes, functions, uses and diversity of people who are using urban spaces and accordingly diversity of 
activities and mode choices. It also encourages public domain with commercial axis that makes streets abundant with life and encourages public spaces as place of resident's interaction, involvement and participation. This can be explained as follow: Its mixed use including retail, shops, education facilities, and other services mixed with residential units makes it provide all sufficient and efficient diversity of activates.

Diversity and mix make streets become vibrant that mostly enough walkability. Its compact mixed-use urban form with services in walking distance reduce travel distance and become welcoming for walkability that increases resident's chances for meeting each other in services area and while they are walking. In addition, its mixed housing income and diversity welcoming public spaces encourages relation between rich and poor and increase the social capital of the city.

Figure (7) revealed that New Cairo records a sole limitation in building types, heights, shapes, functions and type of people who are using streets and spaces. Accordingly streets public urban spaces are negatively affect livability of the city; isolating public streets from its life and creates post-public spaces that encourage collecting people mostly who can pay. This can be explained in term of four causes: first, new Cairo spatial segregated urban form that cuts the continuity between residents; second, new Cairo low density reduces opportunities, choices and chances of types and quantities of human networks and reduces interaction; third, the reliance on single housing income, spelt-diversified residents for homogeneity and limit social interaction inside community to specific social group and exclude the others, and neglect public life; Finally, Its separate use reduces diversity and variation in urban, visual and social relations. New Cairo city relies on single housing income and single use to reduce diversity and accessibility to exclude different housing income groups from urban spaces.

\subsection{Measuring the correlation between social capital and urban form configuration}

\subsubsection{The relation between social capital measure and land use pattern}

Figure (8), reveals that Social capital is reduced in both high mixed and high separated land use pattern, In high mixed use community's residents found that streets are crowded with activities and are full of unknown intrusions, they cannot define strangers and criminals which reduces the trust of others, and reduced safety and security, accordingly they fear to meet the others resulting in reduced interaction, and they want to take their children away from the streets. Also in separate use communities, residents found that streets have no activities as empty; they lost the surveillance to urban space, residents fear to know neighbors. An optimum mix could cause acceptable values of social relations it provides neighboring familiarity; there are limited intrusions or passers-by that make residents feel safe, on the other hand neighbors found common spaces to make them coexist in urban spaces; residents mostly know each other to provide high social relations.

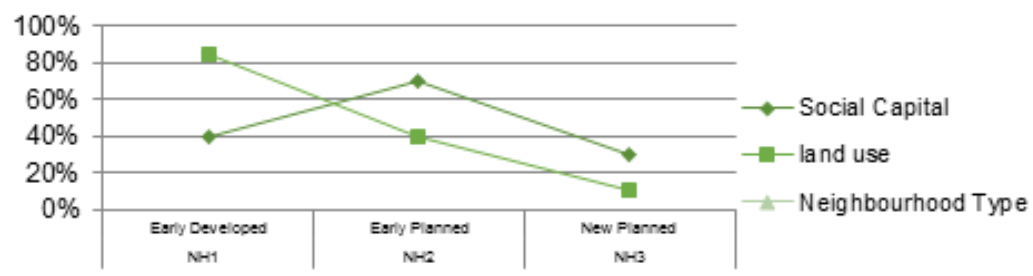

Fig. 8. Relation between neighborhood type and social capital. 


\subsubsection{The relation between social capital measure and housing income pattern}

Fig (9) reveals that Social Capital Measures are reduced in both Shubra and New Cairo, both rely on homogeneity of social fabric that make residents don't have the chance to meet different social group. New Cairo high income residents fair the intrusion of low income offenders; they use different reinforcement methods using physical instruments like gates and fences, monitoring and electronic gates, and alarm systems, and security members. Also Shubra low income residents did not have the chance to meet high income residents. A great social gap and exclusion exist between the community and diverse housing income groups. So both create poles of social tension between the poor and the rich hence enlarge the sense of criminality and vandalism and reduce social capital and accordingly reduce sustainability. On the contrary, Social capital in Heliopolis is increased where diversity of social relations exist, both between neighbors and between intrusions of different social groups who go through in festivals.

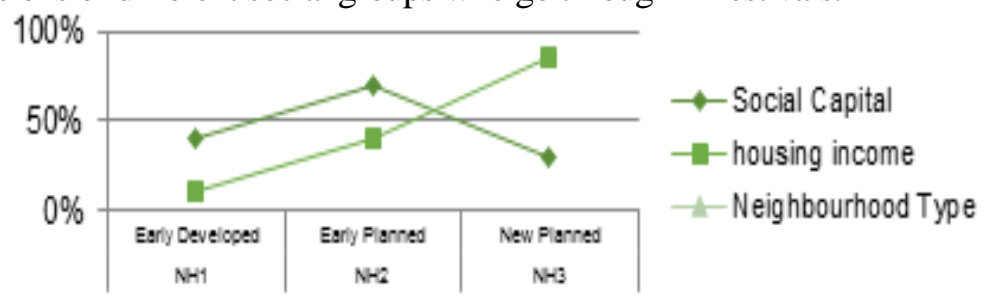

Fig. 9. Relation between housing income pattern and Social Capital.

\subsubsection{The relation between social capital measure and street network pattern}

Figure (10) indicates that social capital is reduced in both cases of Shubra and New Cairo.

The first with extreme hierarchical block and low permeability pattern that decrease through movement of people and record reduced walkability and increased car dependency and accordingly minimize the chances that residents can meet each other and accordingly reduces social interaction, social capital and social sustainability.

The second extreme grid that reduces territorialities and increases through pass that makes offenders are not recognized within strangers and passengers. An optimum value is recorded in Heliopolis with moderate Grid and mixed use patterns that creates friendly walkable communities that enhances intentional and accidental interaction between community residents.

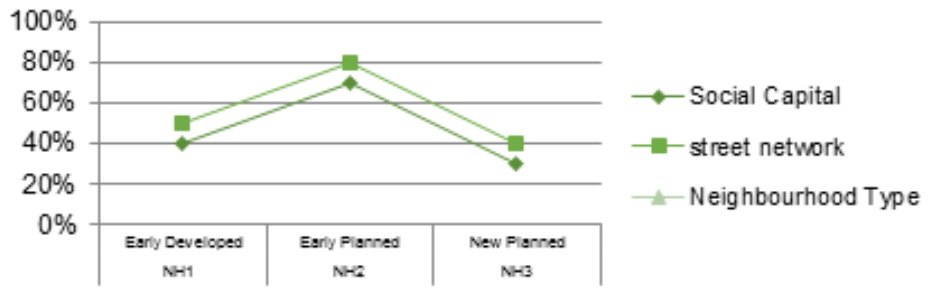

Fig. 10. Relation between street network pattern and Social Capital.

\subsubsection{The relation between social capital measure and density pattern}

Figure (11) reveals that Social capital is reduced in both neighborhoods with very low and very high residential density; the first causes a relevant high increase in community size that makes residents hardly know each other and hardly acknowledge strangers, and fair to build social ties, that caused reduced interaction, mutual relationship, and reciprocity between residents, but at the same time they do not fair to interact with strangers and different community members. The second reduce community size, lost the surveillance to urban spaces. 
On the other hand resident's satisfaction to security and safety issues is reduced in both cases of very low and very high density. The first reduces community size and reduce resident's surveillance to the community. The second is increases community size and accordingly reduces residents familiarity of neighborhoods, and increase the chance of entering offenders between community residents without been known. An optimum value is highly accepted.

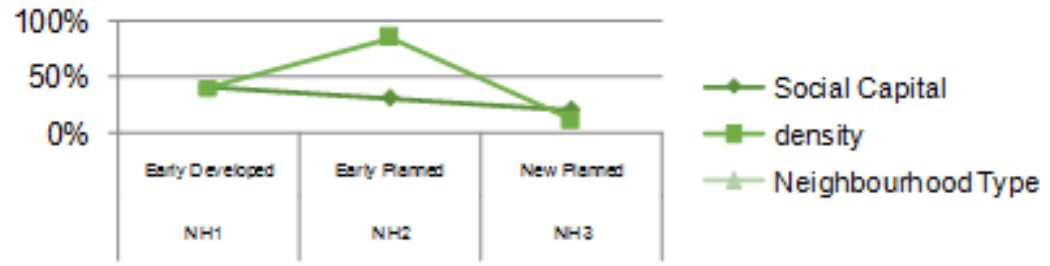

Fig. 11. Relation between housing density pattern and Social Capital.

\subsubsection{The relation between social capital measure and hierarchy urban spaces}

Fig (12) indicates that Social capital are reduced with increasing urban hierarchy of urban spaces, it increases sense of territoriality and makes it become a destination place that lake through pass and by pass product. That makes them easily define strangers; On the other hand resident's satisfaction to security and safety issues is reduced in both cases of grid and treed pattern. The first increase the through pass and increases the unwelcomed persons of the outer community. The second reduces moving persons in streets beside it makes residents completely depend on car movement to cover the large moving distances, the matter that reduces moving pedestrian. An optimum value is highly accepted.

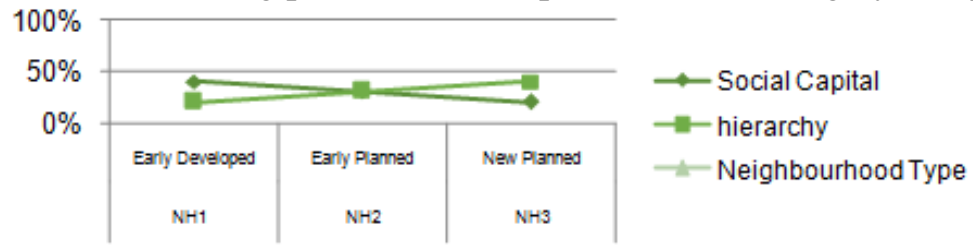

Fig. 12. Relation between urban spaces hierarchy pattern and Social Capital.

This result suggests that traditional neighborhoods that are mixed use, higher in height with higher density, and grid street network oriented, will be higher in their level of achieving than modern car suburbs that are separate use, lower height with lower density, and treed oriented street network.

On the other hand residents satisfaction to safety and security issues are reduced in both cases of traditional, mixed use, high density, and grid street network, and modern, separated use, low density, tree oriented network and car oriented. The first increase density, community size, and existence of strangers and accordingly reduce chance that residents can define and recognize offenders. The second reduce density and remove nonresidential uses that make street are free of passengers that make it become a place that lake surveillance and enhance criminal acts.

A moderate values provide more safe community, mid density, mid mixed use, mid-level, and loop street network are mostly viable to be traced and placed adjacent to criminal low income neighborhoods. It proved its efficiency in facing criminal acts of offenders than the extreme traditional neighborhood with high density, low income, grid street network, and mixed use neighborhood and efficient than the other extreme of contemporary neighborhood with low density, high income, separate use, and treed street network pattern. 


\section{Conclusion and recommendations}

This research suggests that the way we design our neighborhoods affects social capital and thus affects social sustainability. The results indicates three conclusions, the first indicate that fear of perception does not coincide with crime rates accordingly they should be studied separately.

The second regarding residents sense of safety, it indicates that neither residents living in traditional, with extremely densification, mixed use on building level, and grid with high intersection points, nor residents living in modern neighborhood with extremely low density, separate use, and tree street network pattern, are more likely to feel unsafe, during day and night, at homes and in streets, and to feel unsafe for their family and properties. On the other hand, a residents living in moderate neighborhood model are more likely to feel safe, during day and night, at homes and in streets.

The third regarding crime rates, it is recorded that traditional districts compared to modern neighborhoods are more willing to reduce crime rates. It can mitigate the potential risk of criminal focal point to their residents.

Accordingly planners and urban designers are recommended to consider the impacts of neighborhood physical characteristics on crime rates and residents satisfaction:

1- Good design should force a continuous activity in urban spaces, spaces that assure not having negative spaces that increase surveillance. Good design that gives resident's participation a great role in urban design, to found what is suitable for their socio-economic conditions.

2- Both high mixed and high separate use community could encourage criminality. The first increase the existence of strangers and the second remove surveillance from streets, a moderate value of mixed use could achieve better sense of safety and security and at the same time achieve required surveillance to the community.

3- Good design should avoid adjacency to high dissimilar socio-economic neighborhood discourage criminality. It could increase social tension with low income neighbors, and accordingly increase their offender's acts. A lower dissimilarity of socio-economic neighborhood enables residents to interact with different social groups and encourage sense of trust and sense of connection between them and could increase sense of familiarity of other housing income groups, without creating social tension.

4- Both highly grid and treed street network could encourage criminality. The first reduces territorialities and increase the through pass that makes offenders are not recognized within strangers and passengers. The second reduces through movement of people which reduce their eyes continuous vision on the streets. An optimum value is highly accepted.

5- Good design should provide hierarchy in urban spaces, from the public to the private, to improve resident's definition of territoriality, control of access and surveillance; accordingly it could increase sense of safety and security in urban spaces and at the same time increase social relation between residents and enhance social cohesion.

6- Both high and low buildings height and both high and low density could encourage criminality. The first increase community size to an extent that makes residents cannot define strangers and accordingly cannot define offenders. And the second reduce community size to an extent that makes residents cannot have a complete surveillance to their neighborhood. A moderate building height, community density, and community size values proved to be efficient in crime prevention near criminal points. 
A further research with more case studies needs to be carried out to obtain clear conclusions of the relationship between crime and neighborhood patterns.

\section{REFERENCE}

[1] Berube, A. (2005) "Mixed communities in England: A US perspective on evidence and policy prospects" Joseph Rowntree Foundation

[2] Jacobs, J. (1961), the Death and Life of Great American Cities, New York: Vintage Books.

[3] Lofland, Lyn. 1973. A World of Strangers: Order and Action in Urban Public Space. New York: Basic Books

[4] Calthorpe, P. (2003), "The Regional City", time saver - standards - for urban design.

[5] Leyden K. (2003) " Social capital and the built environment: The importance of walkable neighborhoods" American Journal of Public Health, vol 93, No9.

[6] Putnam robert, Robert (1995) “Bowling Alone: America's Declining Social Capital” Journal of Democracy

[7] Putnam robert, Robert (2000) Bowling Alone: The Collapse and Revival of American Community (New York: Simon and Schuster).

[8] Bahamam, Ali Ben Salem (2001), "Hiring Urban design to achieve crime prevention in residential areas" journal of since, medicine and engineering Om El Kora University.

[9] Kamon, Heidar, (1997) " The relationship between urbanization and criminology), El Maousoa Journal (405).

[10] B. Hillier and J. Hanson, the Social Logic of Space, Cambridge University Press, 1984.

[11] Newman, O. (1972). Defensible Space: People and design in the violent city. New York: Macmillan.

[12] Ghonimi I., et.al. (2011), "The Contribution of Gated Communities to Urban Development in Greater Cairo Region", EL Azhara engineering faculty magazine.

[13] Ghonimi, I. (2017 a) "Measuring the correlation between neighborhood models and crime rates and sense of security" Journal of Urban Research Faculty of Urban and Regional Planning Cairo University (JUR).

[14] Ghonimi I., et.al. (2010), "Understanding and formulating gated communities inside Greater Cairo new towns urban fabric", 46th ISOCARP Congress, 19-23 September 2010, Nairobi, Kenya.

[15] Ghonimi, I. (2017 b) " Towards Sustainable New Settlements in Egypt: Lessons Learned from a Comparison between Traditional and Modern Settlements in Greater Cairo Region Egypt" Journal of sustainable development. 


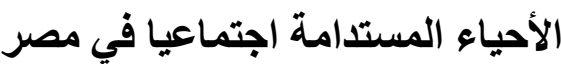

\section{تقييم رأس المال الاجتماعي لنماذج من الأحياء المختلفة في منطقة القاهرة المئمة الكبرى}

$$
\text { الملخص العربى }
$$

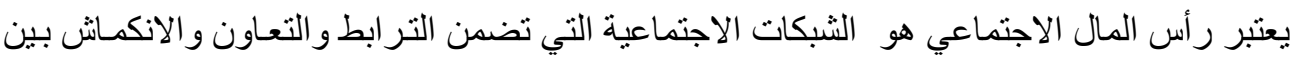

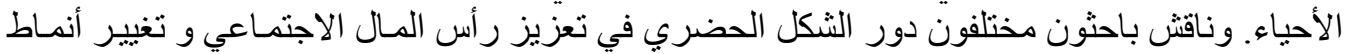

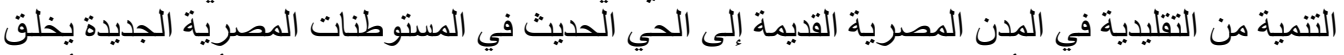

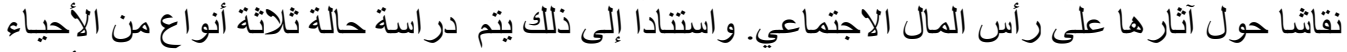

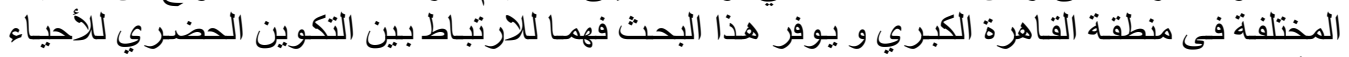
ورأس المال الاجتماعي و الاستدامة الاجنماعية. 